\title{
The diffusion of innovations theory as a theoretical framework in Library and Information Science research
}

\author{
Mabel K. Minishi-Majanjal \\ Department of Information Science, UNISA, P.O. Box 392, Pretoria 0003, South Africa. \\ mkmajanja@yahoo.com
}

and

\author{
Joseph Kiplang'at ${ }^{2}$ \\ Department of Library, Records Management \& Information Studies, Faculty of Information Sciences, \\ Moi University, P.O. Box 3900, ELDORET, Kenya \\ jkngetich@yahoo.co.uk
}

Received: $15^{\text {th }}$ June 2005

Accepted: $9^{\text {th }}$ September 2005

This paper discusses the appropriateness of Diffusion of Innovations (Dol) Theory as a platform for explaining aspects of information and communication technology (ICT) innovation adoption process in the field of Library and Information Science (LIS). The discussion is based on literature review of the theory's application, plus the experience and findings of two recently completed doctoral research projects on ICTs, at the University of Zululand, in which the theory was applied. The Dol theory is essentially a social process in which subjectively perceived information about $a$ new idea is communicated. The theory rests on the premise that a new idea, practice or object has perceivable channels, time and mode of being adopted by individuals or organisations. In recent years, the theory has widely been used to study the adoption of ICTs in organizations and in instructional technology. However, though providing a good tool for descriptive research, the theory does not adequately provide a basis for predicting outcomes or for providing guidance for accelerating adoption rates. There is also doubt about the extent to which the theory can give rise to readily refutable hypotheses. It was also observed that many of the theory's elements are specific to the culture in which it was derived, i.e. North America in the 1950s and 1960s. For instance the theory's "social system" focus, particularly the socio-economic issues, is different from the pertinent issues that continually challenge developing countries such as funding, expertise, politics and culture. Nonetheless, the broad framework of the theory provides a platform for investigating LIS innovations, even in unique social systems such as sub-Saharan Africa's reality.

Key Words: Diffusion of Innovation Theory; Rogers Theory; Theoretical Framework; Information Science Research

\section{Introduction}

The aim of this paper is to describe how the Diffusion of Innovation theory (Dol) has been incorporated in Library and Information Science (LIS) research. The theory was used in two recent studies (Minishi-Majanja, 2004; Kiplang'at, 2004). The purpose of the first study was to investigate the diffusion of Information and Communication Technologies (ICTs) in the communication of agricultural information among agricultural researchers and extension workers in Kenya (Kiplang'at 2004). In particular, the study focused on the public agricultural sector and covered the Kenya Agricultural Research Institute (KARI) and the Ministry of Agriculture and Rural Development (MoARD). It sought to map and audit ICTs in the public agricultural sector in Kenya, establish their nature, types, distribution and extent of use in communication of agricultural information. It assessed the demand and use of ICTs by agricultural researchers and extension workers in their knowledge acquisition and dissemination process. The second study, which aimed to map and audit information and communication technologies (ICTs) in LIS education in sub-Saharan Africa, was conducted against a backdrop of ICTs in higher education, sought to find out the nature and types of ICT knowledge, skills and resources that have been incorporated in LIS education in sub-Saharan Africa (Minishi-Majanja 2004). The aim and objectives of the said study suggested conceptual and theoretical frameworks consisting of technological (ICTs) adoption and educational innovation. It was found pertinent to address both hard and soft technologies and examine the effect of technological developments

I. Mabel K. Minishi-Majanja, PhD, is a lecturer in the Department of Information Science at the University of South Africa

2. Joseph Kiplang'at, PhD, is a senior lecturer in the Department of Library, Records Management \& Information Studies, Faculty of Information Sciences, Moi University, Kenya 
on LIS education. Technological adoption, in the case of LIS was perceived in the forms of soft technology, i.e. innovative ideas and practices, and hard technology, i.e. the ICT products that have transformed both the LIS workplace and hence the education and training for that changed workplace. Educational innovation was found to overlap technological adoption because of the influence of technology on both educational content and educational methods. Rogers' Diffusion of Innovations Theory was considered a suitable framework because of its potential application to information technology ideas, artefacts and techniques, and has been applied as the theoretical framework for a number related studies such as information systems projects (Clarke 1999; Larsen 1997), instructional technology (Surry, 1997; Surry \& Farquhar, 1997), media literacy programmes (Yates, 200I) and telemedicine (Ibbotson, 2000), among others.

\section{The diffusion of innovations theory}

The diffusion of innovation (Dol) theory is essentially a social process in which subjectively perceived information about a new idea is communicated and rests on the premise that a new idea, practice or object has perceivable channels, time and mode of being adopted by individual or organisations (Rogers, 1983). According to Rogers and Scott (1997), the paradigm of diffusion research has its roots in rural sociology research of the 1940s. The key study that influenced its growth was the investigation of the diffusion of the hybrid corn seed among lowa farmers in the United States of America by Ryan and Gross (cited in Rogers \& Scott, 1997). Ryan and Gross purposed to find out the reasons for the hybrid corn seed's success, so as to obtain lessons that might be applied in other farm innovations. Rogers and Scott (1997:4) observe that the findings of that study had far reaching implications beyond agricultural innovations, with the result that by the 1960s, the diffusion model was being applied in a wide variety of disciplines including education, health, communication, business, general sociology and economics. Currently, the diffusion of innovation theory is widely used to study the adoption of innovations such as the Internet and other ICTs (Rogers \& Scott, 1997). To understand the theory, it is important to examine the concepts on which it is built.

Diffusion is a special type of process of 'communication by which an innovation in the form of new ideas, practices or products, is spread, through certain channels, over time, among the members of a social system' (Rogers \& Scott, 1997:4). From this definition, there are four main concepts namely innovation, communication channel, time and social system, which form the four major elements of the diffusion process. These elements are each explained below so as to help in the comprehension of the theory.

An innovation is an idea, practice or object that is perceived as new by members of a social system (Rogers \& Scott, 1997:5). Innovation theorists postulate that certain characteristics determine the rate at which an innovation is adopted by a social system, and these characteristics include relative advantage, compatibility, complexity, trial-ability and observability of the innovation (Rogers \& Scott, 1997:5). Relative advantage is the degree to which an innovation is perceived as better than the idea it supersedes. The degree of relative advantage may be measured in economic terms, prestige, convenience or satisfaction. Accordingly, the greater the perceived advantage, the faster its adoption (Rogers \& Scott, 1997). Compatibility is the degree to which an innovation is perceived as being consistent with existing values, past experiences and needs of potential adopters. Thus, the more compatible with the prevailing social system, the faster the adoption of an innovation because individuals will not, as an initial step, need to also adopt a new value system (Rogers \& Scott, 1997). Complexity is the degree to which an innovation is perceived as difficult to understand and use. According to the theory, ideas that are simpler are adopted more rapidly than complicated ones because the complicated ideas often require individuals/adopters first acquire new knowledge and skills, which can then enable them to understand the new idea (Rogers \& Scott, 1997). Trial-ability is the degree to which an innovation may be experimented with, especially on a limited basis. An innovation that can be tried, especially in instalments, represents less uncertainty and anxiety and hence will be adopted faster (Rogers \& Scott, 1997). Observability is the degree to which the results of an innovation are visible to others. Visibility of results stimulates peer discussion and authenticates the significance of the innovation (Rogers \& Scott, 1997). Thus the relative advantage, compatibility, complexity, trial-ability and observability of an innovation, may singly or combined influence its adoption/non-adoption.

The second element of the Dol theory, Communication Channels, refers to the means by which messages about an innovation are transmitted among members of a social system (Rogers 1995). Information regarding the innovation has to be disseminated so as to introduce the innovation, form or change attitudes, influence decisions regarding the innovation and support the evaluation of the innovation (Rogers \& Scott, 1997). Interestingly, the major channel of communication about ICTs has been these technologies themselves. The third element is time of diffusion, which focuses on three dimensions namely, the decision-making processes, an individual's innovativeness and the rate of adoption (Rogers, 1995). The decision-making process dimension refers to the time involved between the introduction of the new idea, and the decision to accept/reject the new idea. The individual innovativeness dimension refers to the degree to, and rate at which individuals in a social system catch on to a new idea. Rogers and Scott (1997:6-7) postulate that there are five categories 
of adopter innovativeness, namely, innovators, early adopters, early majority, late majority and laggards. In higher education, LIS may be said to be early adopters since in most cases it was LIS services that first adopted computerisation. The rate of adoption dimension of time refers to the relative speed with which a new idea is adopted and is measured in terms of the number of members that adopt the new idea at a given time (Rogers \& Scott, 1997:7-8).

The fourth and last element of diffusion is the social system, which is defined as 'a set of interrelated units such as individuals, groups, organisations, subsystems, that are engaged in joint problem-solving to accomplish a common goal' (Rogers \& Scott, 1997:8). In a social system or unit there are norms, opinion leaders and change agents, which variously influence the diffusion process. For instance, innovation decisions may be optional (where the person or organisation has a real opportunity to adopt or reject the idea), collective (where a decision is reached by consensus among the members of a system), or authority-based (where a decision is imposed by another person or organisation which possesses requisite power, status or technical expertise). The Higher Education social system is often full of bureaucracies that sometimes stifle and at other times facilitate adoption. In many sub-Saharan African countries, these bureaucracies have been accused of being more of impediments rather than facilitating the adoption of innovations.

The above four major elements of the Dol theory as discussed by Rogers (1995), are in fact components from other theories about the innovation process. Rogers combined them so as to create a meta-theory of diffusion (Surry, 1997). Rogers (1995) attempts to present a unified theory by synthesising all the most significant findings related to diffusion from the variety of disciplines. In his 1995 edition of the book Diffusion of Innovations, he presents four of the most widely used theories of diffusion namely, Innovation Decision Process; Individual Innovativeness; Rate of Adoption; and Perceived Attributes.

The Innovation Decision Process proffers that diffusion occurs over time and can be seen as having five distinct stages, namely, knowledge, persuasion, decision, implementation, and confirmation. In other words, potential adopters of an innovation must learn about the innovation, be persuaded as to the merits of the innovation, decide to adopt, implement the innovation, and confirm (reaffirm or reject) the decision to adopt the innovation. Surry (1997) observes that this theory has been widely applied to instructional technology, but points out that, it is often criticised for being change-agent oriented because it emphasises the change agent's role. Rogers' Individual Innovativeness theory states that there are individuals who are predisposed to being innovative, and these will adopt an innovation earlier than those who are less predisposed (Rogers, 1995). This individual innovativeness theory can be seen as a continuum on which at one extreme, there are the "innovators", who are the risk takers and pioneers in adopting an innovation very early in the diffusion process, while at the other extreme are the "laggards" who resist adopting an innovation until rather late in the diffusion process, if ever at all (Surry, 1997:3). In between there are the early adopters, the early majority and the late majority.

The Rate of Adoption theory states that innovations are diffused over time in a pattern that resembles an s-shaped curve, whereby an innovation first goes through a period of slow adoption, then a gradual growth before experiencing a period of relatively dramatic and rapid growth, then stabilisation and finally eventual decline (Surry, 1997). The theory of Perceived Attributes states that potential adopters judge an innovation based on their perceptions in regard to five attributes of the innovation, namely trial-ability, observability, relative advantage, complexity and compatibility (Rogers, 1995). Surry (1997) observes that the theory of perceived attributes has been used as the theoretical basis for several studies relevant to the field of instructional technology because these attributes have been found to play a significant role in several IT-related adoption studies. Surry (1997) cites studies by Wyner, Holloway and Eads, in which relative advantage and compatibility were found to be significant perceptions among potential adopters of instructional technology in high schools.

\section{Relevance of diffusion of innovation theory to ICT research}

Diffusion research, in its simplest form, investigates how the major elements of diffusion, and a multitude of other factors, interact to facilitate or impede the adoption of a specific product or practice among members of a particular adopter group (Surry, 1997). Professionals in a number of disciplines such as Agriculture and Marketing, have used the Dol theory to increase the adoption of innovative products and practices. Clarke (1999) observes that the diffusion theory has potential application to information technology ideas, artefacts and techniques, and has been used as the theoretical basis for a number of research projects on information systems. Likewise, the theory of innovation diffusion has been incorporated into the field of instructional technology in an effort to increase the adoption of instructional technologies because of a growing realisation that innovative instructional products and practices have suffered from a lack of utilisation (Surry, 1997).

Larsen (200I) discusses the applicability of Dol theory using the perspectives of mechanic and organic organisational settings, reaching the conclusion that the diffusion theory has only limited validity. Larsen (200I) argues that no suitable theory of diffusion of Information Science/Technology has been developed as yet and hence, the Dol theory, at best, is an 
umbrella for strategy, innovation, network theory, social structural theory, and a host of other approaches to understanding ICT related change in organisational settings. Surry (1997) concurs that the Dol theory is not one, welldefined, unified, and comprehensive theory, but rather a large number of theories, from a wide variety of disciplines, each focusing on a different element of the innovation process.

Lyytinen and Damsgaard (200I) conducted a critical study that focused on analysing aspects such as the nature of IT, the concept of diffusion arena, the analysis of pull and push forces within Dol research, the view of adopters as rational decision makers, and the presumption that innovating social system has no history, and no feedback. Their findings indicated that IT components should be understood as networked, malleable, and learning intensive artefacts, which are socially constructed. Moreover, the diffusion arenas were volatile, subject to political control and overlapped with several institutional regimes with different interest and concerns. They concluded that the dynamics of constituting diffusion arenas deeply shape the direction and pace of diffusion process and recommended that diffusion researchers should trade generalizability against accuracy and simplicity in their theoretical accounts of IT diffusion, arguing that knowing better and deeper is more important than knowing broader. Lyytinen and Damsgaard (200I) concur that the diffusion of innovations theory draws upon other theories of organisational behaviour adopted from microeconomics, sociology and communication theory.

\section{Application of the Dol theory in two studies}

\subsection{Case one: Dol theory and agricultural information in Kenya}

The purpose of the study was to investigate the diffusion of Information and Communication Technologies (ICTs) in the communication of agricultural information among agricultural researchers and extension workers in Kenya (Kiplang'at 2004). In particular, the study focused on the public agricultural sector and covered the Kenya Agricultural Research Institute (KARI) and the Ministry of Agriculture and Rural Development (MoARD). It sought to map and audit ICTs in the public agricultural sector in Kenya, establish their nature, types, distribution and extent of use in communication of agricultural information. It assessed the demand and use of ICTs by agricultural researchers and extension workers in their knowledge acquisition and dissemination process. It examined government and institutional ICT policies and their effect on diffusion of ICTs in the agricultural sector. The study investigated funding, maintenance and sustainability of ICTs in the agricultural sector and established the knowledge gaps, constraints and challenges encountered in harnessing ICTS in the agricultural sector.

A consideration of the objectives of the study suggested a theoretical framework that has components of technological innovation, adoption, diffusion and communication. Several theories were carefully examined in an attempt to find a theory that encompassed all the components. The theory that was found to be suitable as framework of the study is the Dol theory commonly referred to as Rogers' theory. The theory has potential application to information technology, ideas, artefacts and techniques (Clarke 1999:I). It has been used as the theoretical basis for a number of information systems projects (Rogers and Scott 1999:8, Surry 1997:8, Larsen 1997, Larsen 1998). The theory has also been widely applied to investigate diffusion of agricultural innovations (Rogers and Scott 1999:4, Rogers 1995, Sunding \& Zilberman 2000). Thus the theory's application to information technology and agriculture made it the most appropriate theoretical framework for this study. The strength of the theory is that adopters and non-adopters of an innovation may be studied to identify the factors that influence their adoption behaviour (Lewis 1997:7, Ojiambo 1989:38). Some of these influences include: the nature of the innovation, the communication channels, the characteristics of social group, institutions or organizations (Lewis 1997:7, Ojiambo 1989:38). These factors formed the focus of this study. The next section discusses how the diffusion of innovation theory was applied in the study.

\section{I.I Application of diffusion theory to the study}

\section{I.I.I Agenda Setting}

There are always reasons for introducing an innovation in an organization. As rightly pointed out by Rogers (1995) the innovation process begins with agenda setting where one or more individuals in an organization identify an important problem and then seek an innovation as a means of coping with the problem. Rogers (1995) further observes that the problem usually emanates from a performance gap which is the discrepancy between how the organization is performing in comparison to its potential. He is of the view that the discrepancy is identified by members of the organization and is a strong impetus that compels them to search for an innovation to solve the identified problem.

The agenda setting in the Ministry of Agriculture and Rural Development (MOARD) was prompted by the problem of low agricultural production in Kenya. The main factor that contributed to low production was identified as lack of adequate information support to all stakeholders in agricultural research and extension. In mid July 1996 the MoARD commissioned a study to critically evaluate the existing information landscape, including information flow among actors 
involved in research and extension (Kenya, Republic of, MoARD, 1997:I). The study revealed information deficits due to ineffective agricultural information system. It recommended the establishment of the Agricultural Sector Information Network (ASIN) to acquire, process and disseminate information to the staff of the ministry and other stakeholders (Kenya, Republic of, MoARD 1997:26). The system was to be established at the ministry headquarters and networked directly via communication links to the branches at the provincial and district agricultural offices. It was further recommended that ICTs should be adopted to facilitate communication of agricultural information among all actors involved in research and extension. Similarly, the Kenya Agricultural Research Institute (KARI) found itself ill prepared to contribute to and benefit from cutting-edge information on technological innovations, and was therefore lagging behind (KARI 2002:46). In particular, KARI scientists were not receiving adequate support in terms of accessing reference materials, including scientific journals and databases relevant to their programmes. An Information and Technology Unit was, therefore, established to coordinate adoption and use of ICTs in the institution (KARI 2002:46). The policy makers at MoARD and KARI therefore identified ICTs (innovation) as a solution for improving communication of agricultural information. The innovation in this study was, therefore, ICTs.

The study looks at diffusion as a process by which ICTs (innovation) are communicated through certain channels (e.g. information literacy programmes) over time among agricultural researchers and extension workers (members) at KARI and MoARD (social systems). Rogers and Scott (1999:4) have defined diffusion as the process by which an innovation is communicated through certain channels over time among members of a social system. Thus the four key elements in Rogers's theory fitted well in the study.

\section{I.1.2 ICTs as innovation}

Agricultural researchers and extension workers previously used conventional communication channels to disseminate agricultural information to farmers and other stakeholders. Although these channels have been used widely they have been monologue and have not allowed much interaction. New ways of communication are being adopted via ICTs such as the Internet, email mobile phones, electronic sources among others. ICTs are, therefore, innovations that are perceived as new by both the agricultural researchers and extension workers and have been adopted to facilitate communication of agricultural information

Roger's theory of diffusion of innovations defines five attributes of an innovation which have been shown to affect the rate of its adoption in a society (Cullen 200 I:6). The five attributes also known as characteristics are: relative advantage, compatibility, complexity, trialability, and observability. Perceptions of these attributes have been found to play a significant role in several information technology related studies (Larsen 1997:4). For example Surry (1993) studied the perceptions of weather forecasters in regard to innovative computer-based training and found relative advantage, complexity and compatibility as important adoption considerations. The five attributes are discussed below in the context of the present study.

\section{I.I.3 Relative advantage and compatibility of ICTs among agricultural researchers and extension workers}

The study investigated whether the respondents perceived the use of ICTs in communication of agricultural information as better than the previous mode of communication. It sought to establish the convenience and satisfaction of using ICTs by the respondents as opposed to conventional methods. The rate of adoption of innovations also depends on social prestige. It was assumed that ICTs such as the Internet, email and mobile phone would be adopted faster by the respondents due to their social status and the work-environment that may compel them to keep pace with the technological changes. The change agents, in this case, librarians and IT personnel played a key role in providing information skills programmes and demonstrating to the respondents the relative advantage of ICTs tools and services over previous means of obtaining and communicating agricultural information. Rogers and Scott (1999:8) observe that the greater the perceived relative advantage of an innovation among individuals, the more rapid its rate of adoption will be.

The study found out that although a wide variety of ICT tools and services had been adopted among the institutions surveyed, their relative advantage was still low among the respondents, and in particular the extension workers. It was observed that information literacy programmes were more comprehensive and well co-ordinated at KARI than the Ministry of agriculture. Consequently, most of the agricultural researchers $(83 \%)$ had benefited from information literacy programmes compared to only $39 \%$ of extension workers. Similarly, a significant number $(73.5 \%)$ of agricultural researchers compared to only $36.8 \%$ of extension workers used the Internet in their research and extension work respectively. The findings revealed that an innovation such as ICTs can only be appreciated by the users if they have the necessary skills. The non-availability of ICTs hindered the extension workers from acquiring the basic ICT skills.

The study also sought to establish whether the adopted ICTs in the public agricultural sector were consistent with the values, experiences and needs of agricultural researchers and extension workers. In other words, compatibility of ICTs (innovation) with the needs and aspirations of users may facilitate the rate of adoption. It was necessary, therefore, that 
KARI and MoARD organize continuous ICT training sessions to reduce anxiety and uncertainty among their staff and manage the changes brought about by the new technology. Rogers and Scott (1999:6) caution that adoption of an incompatible innovation often requires the prior adoption of a new value system, which is relatively slow process. The adoption rate of ICTs diffusion would, therefore, depend on good skills, value attached to these technologies and responsive content. It was also found out that use of ICTs was affected by behavioural attitudes, social and economic factors of the respondents.

\section{I.I.4 Complexity of ICTS}

The study sought to establish whether agricultural researchers and extension workers perceived ICTs as complex tools requiring new skills and knowledge. The study found out that that the Internet and email use among agricultural researchers and extension workers was yet to realise its full potential because of lack of computer and Internet literacy skills. Although most of agricultural researchers had basic ICT skills, the majority (88\%) still needed more training on the use of Internet, electronic journals and CD-ROM databases. On the other hand over $95 \%$ of extension workers needed training in all aspects of ICTs. Rogers and Scott (1999:6) note that new ideas that are simpler to understand are adopted more rapidly than innovations that require the adopter to develop new skills and understanding. It was found out that the respondents adopted ICTs such as the mobile phone faster than the Internet since it does not require much skill to use.

\section{I.I.5 Trialability and observability}

Information and Communication Technologies (ICTs) such as the Internet, email, electronic sources require gradual introduction so that users can systematically acquire the necessary skills and knowledge. Information literacy programmes should, therefore, be offered in instalments to allow agricultural researchers and extension workers to gradually acquire the necessary skills and knowledge. The study found out that the information literacy programmes were better coordinated at KARI than the Ministry of Agriculture where such programmes were offered on piece-meal basis. Such a process denies the respondents the opportunity to gradually acquire and retain ICT skills. An innovation that is trialable represents less uncertainty to the individual who is considering it for adoption, who can learn by doing (Rogers 1995:243).

Observability is an attribute which can be "seen" in the process of being used or tried by others and indicates whether an innovation has relative advantage and is compatible (Lewis 1997:13). It was found out that observation and peer discussions had facilitated the adoption and use of ICTs by agricultural researchers. This had been made possible by the fact that out of $21 \mathrm{KARI}$ research centres, 15 had Internet and email services, 5 had email services only and that computers were available to most of the researchers. Besides, KARI had organized several ICT training sessions for its staff. Consequently, many agricultural researchers were able to learn from one another and this facilitated the rate of adoption of ICTs. The application and use of ICTs among the extension workers was curtailed by lack of ICT skills coupled with non-availability of ICTs tools and services.

\section{I.I.6 Reversibility, risks and uncertainty and commitment required in ICT application}

Innovations such as ICTs require good amount of initial capital investment for hardware and software and in developing human resource capacity to manage and maintain the technology effectively (O'Farrell and Norrish 1999:2). Accordingly, discontinuing ICTs diffusion in an organization may lead to a great financial and capital loss. The study found out that despite the efforts to expand and modernize ICTs in the agricultural sector, its growth has been hampered by inadequate funding. This has slowed down the diffusion of ICTs among agricultural researchers and extension workers. Consequently, KARI and MoARD had to content with several constraints including over-reliance on donor projects leading to low level of sustainability and inadequate ICT tools and services. The policy makers at KARI and MOARD should, therefore, plan and this should involve financial and human capital to sustain ICTs in the long run. It was also found out that many donor funded ICT projects have often stalled because of lack of planning, and monitoring and evaluation mechanisms.

Adoption of ICTs requires heavy investment, which may interpret to mean taking high risks. The situation is more volatile in most of the sub-Saharan African countries where the infrastructure may require a face-lift and the need to develop human resource capacity to manage and sustain the technology. The study found out that KARI and MoARD had taken many risks and uncertainties in the process of adopting ICTs. The risks involved included investing so much on acquisition of ICTs at the expense of developing human resource to manage and sustain ICTs.

The success of any ICTs project depends on the adopters' commitment (Rogers 1995). This study found out that although policy makers at KARI and MoARD often commit themselves on paper to acquire and sustain ICTs within their institutions, this was not always fulfilled. The commitment required is in the provision of adequate funds, development of human capacity to manage and use ICTs, and formulation of ICT policy to guide the diffusion process. 


\subsubsection{Communication channels}

Rogers (1995:18) asserts that different communication channels play different roles at various stages in the innovationdecision-process. This study sought to establish the communication channels used in the process of ICTs diffusion among agricultural researchers and extension workers. It was found out that at KARI a variety of methods and techniques were used to create awareness and prepare researchers to effectively use ICTs. The change agents who in this case are the librarians and the IT personnel played an important role in training agricultural researchers to be competent in using the adopted ICTs. The training sessions were conducted at various research centres. Innovations such as ICTs and, in particular, the Internet requires highly developed skills to access and interpret information (Cullen 200I:2). More of such training is needed if agricultural researchers are to effectively utilize Internet services and CD-ROM databases. At MoARD, extension workers were disadvantaged as information literacy programmes were conducted haphazardly. It was only at the Uasin-Gishu district headquarters where the extension workers had been trained on the basic use of computer and Internet. It is, therefore, important to impart the requisite skills to users to facilitate diffusion of ICTs.

This study assessed the communication structures/or networks within KARI and MoARD and how they were being used in channelling ICTs diffusion. Such structures include local and wide area networks and other communication links in place. The study found that Local Area Network (LAN) was being implemented at KARI research centres and at the MoARD headquarters.

\section{I.3 Time}

The policy makers at KARI and MoARD realised that lack of inadequate information support was due to ineffective agricultural information system. Consequently, they instituted measures to improve the situation by adopting use of ICTs in communication of agricultural information. This process took time to conceptualize, plan and implement. Similarly, acquisition of the requisite ICT skills among agricultural researchers and extension workers is a process of gradual growth and so is the ICT use. The rapid growth will only occur when more respondents are ICT literate. This growth is expected to stabilize when the majority of the respondents are able to use ICTs and in particular the Internet, email and electronic sources. The rate of adoption of ICTs among agricultural researchers and extension workers can therefore be graphically represented by Roger's S-shaped or sigmoidal curve.

This study is of the view that the innovation-decision-process is essentially an information seeking and information processing activity in which the individual is motivated to reduce uncertainty about advantages and disadvantages of ICTs (innovation). In other words the policy makers, agricultural researchers and extension workers sought for information to reduce uncertainty on ICTs potential and use during the various stages of innovation-decision- process.

Rogers and Scott (1999:6) define innovativeness as the degree to which an individual or other unit of adoption is relatively earlier in adopting new ideas than other members of a social system. They categorised the adopters into five groups namely: innovators, early adopters, early majority, late majority and laggards. Innovators are the risk takers and pioneers who adopt an innovation very early in the diffusion process (Surry 1997:3). In this study innovators played an important role in the diffusion process by launching the use of ICTs at KARI and MoARD. Such individuals included IT personnel, librarians, agricultural researchers, extension workers, and policy makers who also played the role of gate keeping and channelling of information about ICTs into their institutions. According to Rogers and Scott (1999:7) they are usually the first 2.5 per cent of individuals in organizations to adopt the innovation.

The early adopters were the next to adopt ICTs at KARI and MoARD. They are individuals who maintain a central position in communication networks and would always make judicious innovation decisions. Such individuals are often outgoing and ahead of others. They are usually respected by their peers, and are the embodiment of successful, discrete use of new ideas. At KARI and MoARD such individuals were the directors of research centres and district agricultural officers and because of their proactiveness, they initiated the adoption of ICTs earlier than others. Not all KARI Research Centres were moving at the same pace in adopting ICTs. For example, Mtwapa, Kitale, Kisii, Katumani, Thika, and NARL research centres were ahead of others. Similarly, the Uasin-Gishu district agricultural was fairing on well than Baringo district agricultural office. Early adopters play an important role in influencing others by conveying subjective evaluation of ICTs (innovation) to near-peers through interpersonal networks. They may have consisted of 13.5 per cent of the population at KARI and MoARD.

The early majority are categorised as those respondents who may deliberate for sometime before completely adopting ICTs such as the Internet, email and electronic sources. Rogers and Scott (1999:7) are of the view that early majority may be willing to adopt an innovation, but opt for others to lead the way. Accordingly, they say, the early majority consist of 34 per cent of the individuals in an organization.

The late majority in this study represent those respondents who were sceptical and cautious to adopt and use ICTs until the majority have done so. They only adopt and use after increasing pressures from colleagues. Often other factors 
such as behavioural attitude, social and economic status and lack of skills slow or impede their adoption and use of ICTs. According to Rogers (1995) the late majority consist of 34 per cent of individuals in an organization. Most of the extension workers fitted well in this category of users

The laggards were agricultural researchers and extension workers who were resistant to ICTs adoption and use in the agricultural sector. They may have resisted due to limited resources or because of their past experience. This group are usually suspicious of change agents who may include IT personnel, librarians and probably policy makers. Because of uncertainties of the new changes some may opt for a 'wait and see' attitude.

\section{I.4 The social system}

The Kenya Agricultural Research Institute (KARI) and the Ministry of Agriculture and Rural Development (MoARD) were regarded as the social systems in this study. These institutions have a set of interrelated units consisting of agricultural offices, research centres, divisions and departments. The staff members in these units work according to the established mission of their respective institutions and, therefore, share the common objective that binds them together. KARI and MoARD are working together towards solving the problem of low agricultural productivity in the country. Lack of adequate information support to actors involved in research and extension has been identified as a major cause of low agricultural production. Consequently ICTs were adopted to improve information flows and communication of agricultural information between and among all actors. Rogers (1995:37) notes that the social or communication structure of a system could facilitate or impede the diffusion of innovation in a system. KARI and MoARD have established information divisions within their structures to coordinate information activities within the respective institutions. The two institutions have established agricultural knowledge and information systems with the sole purpose of providing agricultural information to agricultural researchers and extension workers.

Calvo and Rahrig (1999:2) caution that person(s) introducing an innovation in a social system should take into consideration the characteristics of the target population and the innovation itself. Accordingly, they assert that knowing these characteristics provides for proper planning to avoid disruptive effect on the social environment. These views were shared by this study which established the characteristics of agricultural researchers and extension workers and showed their relationships in the application and use of ICTs. While the agricultural researchers had higher qualifications, the extension workers had lower qualifications. Besides, the majority of agricultural researchers had received their training in overseas universities and were more likely to have been exposed to the use of ICTs compared to the majority of extension workers who were trained locally in the country. The job orientation of the two categories of respondents affected the use of ICTs. For example, agricultural researchers utilized the Internet and email services more than the extension workers due to their nature of work.

It was also established that the policy makers at KARI and MoARD had taken into consideration some of the demands and needs of agricultural researchers and extension workers before introducing the use of ICTs. But this had not been implemented fully due to inadequate funds, lack of IT personnel and poor communication infrastructure. Rogers and Scott (1999:7) explains that a change agent is an individual who attempts to influence clients' innovation-decisions in a direction that is deemed desirable by a change agency. In this study, policy makers, IT personnel, librarians are considered as important change agents with the responsibility of facilitating the adoption and use of ICTs at KARI and MoARD.

Redefining or restructuring is the stage at which the innovation is modified and re-invented to fit the situation of the particular organization and its perceived problem (Rogers 1995). Glanz, Lewis and Rimer (1997) observe that it is important for an innovation to be modified or re-invented over time. Accenture, Markle and UNDP (200I:I) underscores the importance of designing and shaping ICTs to be demand-driven and meet the needs of the target population. This concurs with the views of Larsen (1997:I) who observes that adopters of ICTs usually mould the innovation in accordance with their own perceptions and needs. The study sought to establish how KARI and MoARD are moulding or redesigning ICTs to suit the needs and demands of agricultural researchers and extension workers. These may include development of interfaces, in-house databases and also networking of offices to facilitate information flows among the staff. This is what Rogers (1995) refers to as altering organizational structures to accommodate the innovation. The study assumed that the ultimate goal of KARI and MOARD is to put ICTs into full and regular use to the point where they become part and parcel of institution ongoing activities. The study found out that because of lack of IT personnel to manage and maintain ICTs at KARI and MOARD not much had been done as far as modification of ICTs is concerned. It was only at seven KARI research centres where Local Area Network (LAN) had been installed and this enabled researchers to communicate and access Internet and email services. Attempt was being made to network other KARI research centres using satellite and Very Small Aperture Technology (VSAT). It was found out that more is needed to be done on the provision of local content. 


\subsection{Case two: ICTs in LIS education in Africa}

The Diffusion of Innovation (Dol) theory was used to map and audit information and communication technologies (ICTs) in library and information science (LIS) education in sub-Saharan Africa (Minishi-Majanja, 2004). The study, which was conducted against a backdrop of ICTs in higher education, sought to find out the nature and types of ICT knowledge, skills and resources that have been incorporated in LIS education in sub-Saharan Africa. LIS is an innovation-based discipline because all its professional activities require innovative application of knowledge, skills and technology. Moreover, LIS is inextricably linked with ICTs and ICT-related transformations. In cognisance of this vital role of ICTs in current global integration efforts and standards, the study sought to investigate the status of ICTs in LIS programmes as a means of assessing ICT capacity in sub-Saharan Africa, with specific reference to the Library and Information science discipline.

The aim and objectives of the said study suggested conceptual and theoretical frameworks consisting of technological (ICTs) adoption and educational innovation. It was found pertinent to address both hard and soft technologies and examine the effect of technological developments on LIS education. Technological adoption, in the case of LIS was perceived in the forms of soft technology, i.e. innovative ideas and practices, and hard technology, i.e. the ICT products that have transformed both the LIS workplace and hence the education and training for that changed workplace. Educational innovation was found to overlap technological adoption because of the influence of technology on both educational content and educational methods. Rogers' Diffusion of Innovations Theory was considered a suitable framework because of its potential application to information technology ideas, artefacts and techniques, and has been applied as the theoretical framework for a number related studies such as information systems projects (Clarke 1999; Larsen 1997), instructional technology (Surry, 1997; Surry \& Farquhar, 1997), media literacy programmes (Yates, 200I) and telemedicine (lbbotson, 2000), among others.

\subsection{General profile of LIS education and ICT infrastructure in Africa}

LIS education and training occurs in universities, an indication of adequate academic standards and professionalism because the parent universities usually impose internationally comparable standards for all the programmes offered. Rosenberg (2000) quotes Harris's conclusion that "the centring of the library school within university is generally recognized as desirable..." in order to safeguard the integrity of certificates, diplomas and degrees as well as attract quality staff, students and professional recognition. However, this indication should not be viewed as a judgement over the quality of other tertiary level institutions, as that is neither the mandate, nor within the scope of this study. Rather, as observed by Rosenberg (2000), there was a trend for para-professional and non-professional programmes to be offered outside universities because "universities are expensive locations for non-graduate education and training." But this trend may be interrupted as further transformation of higher education takes place. For instance, higher education institutions in South Africa are merging into "comprehensive" institutions that are expected to offer qualifications ranging from certificates and diplomas to doctorates. What is more significant to this study is the fact that higher education as a sector and universities in particular, have already adopted the ICT innovation and what may be at variance is the level of ICT adoption that each country and/or university has attained. In most cases, the whole diffusion process from the decision making to adoption was done at a higher level that the LIS school. In some cases, depending on individual institutions, a great amount of input was sought from the academic departments before institutional management makes the final decision. Nevertheless, at operational level, LIS schools are still subject to making certain decisions in the adoption process.

An important indication of adoption of an innovation is the formulation of a policy to guide the development and use of the adoption. Twenty three (79\%) parent institutions that host LIS schools have ICT policies that regulate the development of the internal infrastructure. However, only eleven of these were reported to explicitly include the ICT goals of the respective LIS school. But of the II institutions that had explicitly included LIS goals in their policy, 8 had a separate ICTs budget. It is important for the goals and needs of the department to be included as this tends to have implications on the budget, infrastructural plans and other support. However, some of the LIS schools that did not have a separate budget explained that the ICT budget, like the rest of the ICT administration, was centralized within their institution.

The types and levels of computerization set-ups within the LIS schools indicates the level of networking and hence functionality of ICTs within the department, the institution as well as the rest of the computerised world. It was found that students' physical access to computers was poor since only $45 \%$ of the respondents reported that physical access was at the computer-student ratio of $1:>6,14 \%$ provide at the ratio of $1: 6-20$ and $10 \%$ provide at the ratio of $I:<20$. Physical access for staff was generally better because $57 \%$ provide access at $1: 1$ ratio and $17 \%$ provide $1: 2-5$ staff-computer ratios. Seventeen $(59 \%)$ of the LIS schools had stand-alone and in five of these, those stand-alone computers were all there was. However, $18(62 \%)$ of the LIS schools had departmental computer laboratories, 14 (48\%) of which had 
departmental/LIS school networks. Sixteen (55\%) had campus/institutional laboratories, I 4 (48\%) had campus-wide local area networks (LANs), and 10 (35\%) operated in a multi-campus network set-up. A decentralised set-up involving a departmental laboratory and/or network(s) facilitates specialised use, say, of special software, databases and other configurations that are appropriate for LIS teaching/learning. However, for logistical and financial planning purposes, some institutions favour the centralized approach. In so far as Internet access is concerned, responses showed that 22 (76\%) of the LIS schools had access to the Internet and it was accessible to both staff and students. However, in a few institutions, the cost of Internet use for the staff and students was not always met by the institution but instead Internet access was provided in a café rather than offices or laboratories and the cost/fee was met by each user on a pay-as-you-use basis. Thus $3(10 \%)$ of the deans/directors of LIS schools indicated that they paid from their pockets for Internet use, $2(7 \%)$ of the heads of departments had to pay, while academic staff in 3 (10\%), students in $2(7 \%)$ and administrative staff in 2 (7\%) of the LIS schools had to pay individually in order to access the Internet.

\subsubsection{Diffusion of ICTs in teaching and learning}

The study used thirteen teaching/learning activities and requested respondents to indicate the extent to which ICTs are generally used in each using a Likert scale of three categories namely 'always', 'sometimes' and 'not at all'. Table I shows average percentage use of ICTs for the individual teaching/learning activities.

Table I ICT use in Teaching/Learning activities

$$
\mathrm{N}=29
$$

\begin{tabular}{llll}
\hline Teaching/Learning Activity & Always using ICTs & Sometimes using ICTs & Total \\
\hline & No. $(\%)$ & No. $(\%)$ & No. $(\%)$ \\
Computer literacy & $20(69 \%)$ & $6(21 \%)$ & $26(90 \%)$ \\
Lecture presentation & $8(28 \%)$ & $17(58 \%)$ & $25(86 \%)$ \\
Access remote resources & $12(41 \%)$ & $11(38 \%)$ & $23(79 \%)$ \\
Access academic content & $12(41 \%)$ & $11(38 \%)$ & $23(79 \%)$ \\
Curriculum development & $10(35 \%)$ & $12(41 \%)$ & $22(76 \%)$ \\
Students feedback & $8(28 \%)$ & $13(45 \%)$ & $21(73 \%)$ \\
Local websites & $10(35 \%)$ & $11(38 \%)$ & $21(73 \%)$ \\
Assignments and/or projects & $7(24 \%)$ & $13(45 \%)$ & $20(69 \%)$ \\
Improving the management of courses & $8(28 \%)$ & $11(38 \%)$ & $19(66 \%)$ \\
Support to the teaching methods & $5(17 \%)$ & $14(48 \%)$ & $19(66 \%)$ \\
Collaborative teaching & $4(14 \%)$ & $11(38 \%)$ & $15(52 \%)$ \\
Distance learning & $3(10 \%)$ & $10(35 \%)$ & $13(45 \%)$ \\
Bulletin boards & $7(24 \%)$ & $2(7 \%)$ & $9(31 \%)$ \\
\hline
\end{tabular}

The general observation was that except in only two activities, Distance Learning and Bulletin Boards, most of the LIS schools use ICTs in most aspects of teaching and/or learning. However, the use of ICTs in most of these activities is limited, implying that for majority of the teaching and learning activities, LIS schools resort to manual and offline action.

Online teaching does not always mean a total exclusion of class contact, but may reduce contact time. However, it was also noted that some students may opt not to attend scheduled face-to-face classes in favour of the online delivery only. Only a few, 10 (34\%) of the African LIS schools practice some online teaching and learning. These include Kenya School of Professional Studies, Rand Afrikaans University, Stellenbosch University, Technikon South Africa, University of Ghana, University of Natal, University of Pretoria, UNISA, University of Zululand, and the Zimbabwe National University of Science and Technology. At three of these institutions, Rand Afrikaans University, Stellenbosch University and University of Pretoria, all postgraduate courses are offered online. Four LIS schools, i.e. at Rand Afrikaans University, Stellenbosch, UNISA and University of Pretoria, at least partially support all undergraduate courses with online courseware. The Kenya School of Professional Studies was attempting collaborative distance education with a university in South Africa. At the University of Dar-es-Salaam, Blackboard courseware had been acquired and the LIS school was in the process of preparing course material for implementation.

Overall, individual modules that are fully taught online include Advanced/Online Information Retrieval, Information/ Knowledge Management (I), Information Technology (Tools, Applications, etc.), and Web-based Information systems/ Online retrieval systems. Modules that are partially taught online include Advanced/Online Information Retrieval (10\%), Applied Information Science (3\%), Automation of Library and Information Services (3\%), Database management/ Applications (3\%), Electronic/Media Publishing and/or Production of Information (3\%), Information / Knowledge Management (3\%), Information Organization and Processing (3\%), Information Storage and Retrieval (3\%), Information Service/Work (3\%), Information Technology (Tools, Applications, etc.) (10\%), Internet Searching (7\%), Internet Services (3\%), Library Automation, (10\%), and Management of Electronic Records (7\%). 


\subsubsection{Diffusion of ICTs in research activities}

There was generally high usage of ICTs in research activities with the highest use in information retrieval, that is, using the technologies to collect research information, for which $90 \%$ of the respondents indicated that they used ICTs. This was followed by use in the disseminating research information $79 \%$, ICTs as research tools $76 \%$, for collaborating with other researchers, $76 \%$, and for creating national and international research networks $66 \%$. The lowest use was for the activities of group conferencing with $45 \%$ use and Intranet electronic publishing of research results/reports with $52 \%$ use.

\subsubsection{Diffusion of ICTs in administration and management}

Effective use of ICTs in academic management activities requires the use of intranets and/or local area networks. Such a network not only connects the various constituents of academic administration such as admission and registration, students' finance, course offerings, examinations and even students' accommodation, but a network also facilitates the sharing of data, thus minimising costs and errors. An intranet or campus internal network provides a cheaper and easier way of sharing information at institutional level, without which a lot of duplication in services results. Twenty-one (72\%) LIS schools are linked to a campus intranet, of which $12(41 \%)$ provide staff access both from home and at the office and $9(31 \%)$ provide students access both on campus and away from campus.

The study used ten areas/activities of academic administration in which ICTs can be applied. For each activity, respondents were required to indicate whether their school uses ICTs "always", "sometimes" or "not at all. It was found that for all the activities, there was a high rate of computerisation. Academic records administration was found to have the highest $(86 \%)$ computerisation rate, followed by students' registration activities - $79 \%$, financial administration $69 \%$, Internal communication - $69 \%$, support to management decisions - $69 \%$, office automation - $66 \%$, personnel administration - $62 \%$, interaction with stakeholders - 59\%, and assets maintenance $-56 \%$.

The theory was not an exact match or 'tight fit' for this study, but its principles provided a suitable framework and/or backdrop for this research addressing ICTs.

\section{Comparative overview of results}

Table 2 Diagrammatic summary of the Dol theory results in the two studies

\begin{tabular}{|c|c|c|}
\hline & $\begin{array}{l}\text { ICTS IN AGRICULTURAL } \\
\text { INFORMATION (Kenya) }\end{array}$ & $\begin{array}{l}\text { ICTs IN LIS EDUCATION } \\
\text { (sub-Saharan Africa) }\end{array}$ \\
\hline \multicolumn{3}{|l|}{ I. THE INNOVATION } \\
\hline Relative Advantage & $\begin{array}{l}\text { Low (lack of knowledge, skills and } \\
\text { resources) }\end{array}$ & High (current trend in professional practice) \\
\hline Compatibility & $\begin{array}{l}\text { - New value systems and practices } \\
\text { - no moulding or redesigning to suit the } \\
\text { needs and demands }\end{array}$ & $\begin{array}{l}\text { Acceptable (fundamental ideas of LIS are inherent in ICT } \\
\text { development) }\end{array}$ \\
\hline Complexity & $\begin{array}{l}\text { Cell-phones less complex than Internet } \\
\text { and E-mail }\end{array}$ & $\begin{array}{l}\text { Both hard and soft technology increasingly complex (vis a } \\
\text { vis expertise of educators) }\end{array}$ \\
\hline $\begin{array}{l}\text { Trialability (Reversibility, } \\
\text { risks, uncertainty \& } \\
\text { commitment) }\end{array}$ & $\begin{array}{l}\text { - Risks \& uncertainties prevalent } \\
\text { (funding, success) } \\
\text { - On 'paper' commitment by mgnt. }\end{array}$ & $\begin{array}{l}\text { (bureaucracy and cost factors) } \\
\text { - Risks (institutional) } \\
\text { - Uncertainties (staff competence) }\end{array}$ \\
\hline Observability & $\begin{array}{l}\text { (KARI vs. MoARD) } \\
\text { - observation - KARI stations } \\
\text { - peer discussions ( researchers) }\end{array}$ & Visible \\
\hline $\begin{array}{l}\text { II. COMMUNICATION } \\
\text { CHANNELS }\end{array}$ & Mainly through training & $\begin{array}{l}\text { Interpersonal communication, peer conversation, } \\
\text { conferences, workshops, publications, training }\end{array}$ \\
\hline \multirow[t]{2}{*}{ Change agents } & Librarians \& IT specialists & IT specialists (within and outside LIS) \\
\hline & $\begin{array}{l}\text { ICTS IN AGRICULTURAL } \\
\text { INFORMATION (Kenya) }\end{array}$ & $\begin{array}{l}\text { ICTS IN LIS EDUCATION } \\
\text { (sub-Saharan Africa) }\end{array}$ \\
\hline \multicolumn{3}{|l|}{ III. TIME } \\
\hline $\begin{array}{l}\text { Innovation-decision process } \\
\text { (knowledge, persuasion, } \\
\text { decision, implementation, } \\
\text { confirmation) }\end{array}$ & $\begin{array}{l}\text { Took a long time to conceptualize, plan } \\
\text { and implement }\end{array}$ & $\begin{array}{l}\text { Takes a long time } \\
\text { - knowledge and persuasion; conferences \& } \\
\text { interpersonal communication } \\
\text { - decision and implementation » subject to institution, } \\
\text { infrastructure, negotiation, funds and expertise. }\end{array}$ \\
\hline
\end{tabular}




\begin{tabular}{|c|c|c|}
\hline $\begin{array}{l}\text { Individual innovativeness } \\
\text { (innovators, early adopters, } \\
\text { early majority, late majority, } \\
\text { laggards) }\end{array}$ & $\begin{array}{l}\mathrm{I}=\mathrm{IT} \text { personnel, librarians, agricultural } \\
\text { researchers, extension workers, and } \\
\text { policy makers } \\
E A=\text { directors of research centres } \\
L=\text { agricultural researchers and }\end{array}$ & $\begin{array}{l}\text { (hard to determine) } \\
\text { - varying levels of exposure (institutional, personal, } \\
\text { social/home background) } \\
\text { - Late majority (pressure from global trends) }\end{array}$ \\
\hline \multirow[t]{2}{*}{ Rate of Adoption } & Sigmoidal curve (S-shaped & Slow start, gradual increase. \\
\hline & $\begin{array}{l}\text { ICTs IN AGRICULTURAL } \\
\text { INFORMATION (Kenya) }\end{array}$ & $\begin{array}{l}\text { ICTs IN LIS EDUCATION } \\
\text { (sub-Saharan Africa) }\end{array}$ \\
\hline \multicolumn{3}{|l|}{ IV. SOCIAL SYSTEM } \\
\hline Social structure & $\begin{array}{l}\text { - Government dept. (MoARD) \& } \\
\text { Research Institute (KARI) } \\
\text { - Inter-related agricultural offices, } \\
\text { research centres, divisions and } \\
\text { departments } \\
\text { - agricultural researchers (higher } \\
\text { qualifications), extension workers (lower } \\
\text { qualifications) }\end{array}$ & $\begin{array}{l}\text { - Hierarchical administrative structures within respective } \\
\text { academic institutions } \\
\text { - Informal relationship with Stakeholders (i.e. employers, } \\
\text { practitioners, counterparts, students) }\end{array}$ \\
\hline Norms & $\begin{array}{l}\text { "Agricultural productivity" } \\
\text { - established mission and norms } \\
\text { - established agricultural knowledge and } \\
\text { information systems }\end{array}$ & "Information business" \\
\hline Opinion leaders & Directors and Researchers & (not identified) \\
\hline
\end{tabular}

\section{Shortcomings of DOI theory on the studies}

Critics of the theory include Clarke (1999) who argues that the Diffusion of Innovation Theory is at its best as a descriptive tool, less strong in its explanatory power, and less useful still in predicting outcomes, and providing guidance as to how to accelerate the rate of adoption. He further argues that there is doubt about the extent to which it can give rise to readily refutable hypotheses because many of its elements may be specific to the culture in which it was derived (viz. North America in the 1950s and 60s), and hence less relevant in East Asian and African countries. However, the current studies, being largely descriptive, exploited this aspect of the theory. Rogers (1995) himself argues that although diffusion research has made numerous important contributions in understanding human behaviour change, its potential would have been even greater had it not been characterized by shortcomings and biases. He contends that pro-innovation bias is caused by change agencies that fund much of diffusion research with the aim of promoting an innovation. This was the case with many donor-funded ICT projects at KARI and MoARD. Once the donor funding ended it was difficult for the institutions to sustain the ICT projects. Rogers (1995) identified the second cause as being where most diffusion researchers investigate successful diffusions, leaving those, which are not successful. This is often attributed to the fact that successful innovations usually leave a rate of adoption that can be retrospectively investigated by diffusion researchers, while unsuccessful diffusion does not leave visible traces that can be easily studied.

Rogers (1995) suggests that the problem of pro-innovation bias can be overcome by investigating an innovation while the diffusion process is still underway. He observes that such an in-process diffusion research design allows a scholar to investigate less successful as well as more successful cases of innovation diffusion. This shortcoming did not affect these studies as ICT diffusion is an on-going activity that needs to be evaluated from time to time and improved according to the changing needs of the users. One of the studies investigated both successful and unsuccessful ICT adoption at KARI and MoARD. It established whether the adopted ICTs were meeting the needs of agricultural researchers and extension workers. It investigated cases where particular type of ICTs had been modified or re-invented to suit the demands and needs of agricultural researchers and extension workers. The shortcomings of diffusion of innovation theory, therefore, did not affect this study.

\subsection{Appropriateness for developing countries}

Rogers (1983) observes that the classical diffusion model was developed from a reality of socio-economic conditions and by scholars with an ideological position not compatible with the reality of the developing world. To support his point, Rogers cites a 1976 study by Bordenave, which recommended that Latin American communication researchers must refrain from perceiving their reality through foreign concepts and ideologies because such a perception does not enable them to get to the main issues affecting development (Bordenave, cited in Rogers, 1983). Rogers concludes that diffusion research in developing countries should focus on equity issues rather than innovation. This view has partially been corroborated by various African scholars in so far as ICTs are concerned because to some extent, it is not ICTs as an 
innovation that is usually the issue (Aina, 1993; Ajayi, Isalawu and Raji, 1999; Alemna, 1999; Kloppers, 1996; Ocholla 2002; Thapisa \& Birabwa, 1998). Rather, it is the socio-economic reality as well as other issues of finances, human resource capacity, politics and culture that have great influence on the diffusion of any innovation. In a way, one of the current research reveals the preponderance of socio-economic problems that do not leave a clear scene for investigating on the strict and narrow principles of the diffusion of innovation theory. Nevertheless, the findings of this study have pointed out the need for further investigation into issues relating to socio-economic, human resource, politics and culture.

\subsection{Centralised vs. Decentralised diffusion systems}

The diffusion model is based on a centralised system whereby an innovation originates from an expert source to passive potential adopters who accept or reject the new idea. Rogers (1983:333-334) observes that this centralisation is because of "the fact that the basic paradigm for diffusion research grew out of the Ryan and Gross's 1943 hybrid corn study, which was based on the centralised agricultural development system of USA at the time," and thus influenced the formulation of the diffusion model. Although the classical diffusion model is relevant in much of current reality, it is criticised by Schon (as cited in Rogers, 1983:334) for its failure to "capture the complexity of relatively decentralised diffusion systems in which innovations originate from numerous sources and evolve as they diffuse via horizontal networks." Rogers (1983) concurs that some new ideas are decentralised, diffusing horizontally through informal networks with a high degree of modifications occurring as adopters try to fit the innovation in their particular circumstances. ICTs are one such innovation, whereby there is no overall control by governments or strict top-down diffusion. Neither can the ICT industry be defined in top-down terms because various disciplines and industries (social systems) converge to make the whole. Instead, there is wide sharing of power among members of the various social systems and a great deal of local experimentation and remodelling by adopters (Rogers, 1983).

\section{Conclusion}

This paper has discussed the theory of Dol and how it can be applied in the adoption of ICTS in LIS education and agricultural information systems. The theory provides a good tool for descriptive research and these studies exploited this aspect of the theory. However, the theory does not adequately provide a basis for predicting outcomes as well as providing guidance as to how to accelerate the rate of adoption. Additionally, the theory's focus is best applied on the socio-economic issues of ICTs in the social system. Despite its shortcomings, the theory is sufficiently robust in explaining the adoption and/or diffusion and non-adoption and/or non-diffusion of ICT innovations than any other theory. It is suggested that in order to maximize the potential benefit of diffusion theory, it may be necessary for instructional technologists to adopt a more instrumentalist philosophy of technology, while keeping some elements of the determinist philosophy. Diffusion arenas are volatile, subject to political control and they overlap with several institutional regimes with different interest and going concerns. The dynamics of constituting diffusion arenas can deeply shape the direction and pace of diffusion process. This paper concurs with an earlier suggestion, from previous similar studies, that diffusion researchers have to trade generalizability against accuracy and simplicity in their theoretical accounts of the diffusion of ICTs.

\section{References}

Calvo, A \& Rahrig, K. 1999. Diffusions of Innovations. University of South Florida: community and Family Health. [online] http:// hsc.usf.edu/ kmbrown/Diffusion_of_Innovations_Overview.htm. Accessed 20 June 2002.

Clarke, R. 1999. A Primer in Diffusion of Innovations Theory. [online] http://www.anu.edu.au/people/Roger.Clarke/SOS/ InnDiff.html. Accessed 18 November 2002.

Cullen, R. 200I. Addressing digital divide. IFLA proceedings of 67th Council and General Conference. Boston: IFLA.

Glanz, K, Lewis FM. \& Rimer, BK. 1997. Health behaviour and health education: theory, research and practice. 2nd ed. San Francisco, CA: Jossey-Bass Publishers.

Ibbotson, T. 2000. An ethnographic study of the diffusion of telemedicine in Scotland. [online] http://virtualsociety.sbs.ox.ac.uk/ projects/ibbotson.html. Accessed 26 Novemebr 2002.

Kenya Agricultural research Institute. 2002. Third medium term plan July 2003 to June 2008. KARI: Nairobi.

Kenya, Republic of, Ministry of Agriculture and Rural Development. 1997. Assessment of information needs and of options of management: second post study workshop report. Nairobi: MoARD.

Kiplang'at, J. 2004. Diffusion of Information and Communication Technologies in the communication of agricultural information among agricultural researchers and extension workers in Kenya. (Unpublished Doctoral Thesis). University of Zululand.

Larsen, TJ. 1997. Diffusion Theory as the Basis for Understanding Information Technology Related Change: True or False? [online] http://infomgt.bi.no/research/tor-innovation/pr-diffusion.htm. Accessed I8 November 2002.

Larsen, TJ. 1998. Information systems innovation: A framework for research and practice: In Larsen, T.J. and McGuire, E. (Eds). Information systems innovation and diffusion: issues and directions. Hersey, PA: IDEA Group Publishing, 4I I-434.

Larsen, T]. 200I. The phenomenon of diffusion: red herrings and future promise. [online] http://www.ucalgary.ca/ marcolin/ifip86. Accessed 14 November 2002. 
Lewis, GA. 1997. Leadership products as innovations in context of Rogers' Diffusion Theory. Ph.D. dissertation. Virginia Polytechnic Institute and State University.[on-line] http://scholar.lib.vt.edu/theses/available/edt-/1997-/767/unrestricted/EDT.PDF [accessed 18/6/02].

Lyytinen, K \& Damsgaard, J. 200I. What's wrong with the diffusion of innovation theory: the case of a complex and networked technology; working paper R-98-5010, Institute for Electronic Systems, Department of Computer Science, Aalborg University. [online] http://www.ucalgary.ca/ marcolin/ifip86. Accessed I4 November 2002.

Minishi-Majanja, MK. 2004. Mapping and Audit of Information and Communication Technologies in LIS Education in sub-Saharan Africa (Unpublished Doctoral Thesis, 2004), University of Zululand.

O'Farrell, C, Norrish. P \& Scott, A. 1999. Information and Communication Technologies for sustainable livelihoods: Preliminary study. [online] htpp.//www.rdq.ac.uk/AERDD/AERDD/ICTs.html. Accessed I 5 July 2002.

Ojiambo, JB. 1989. Communication of agricultural information between research scientists, extension personnel and farmers in Kenya. Ph.D. Thesis (unpublished). University of Pittsburgh.

Rogers, EM. 1983. Diffusion of innovations. (3 ${ }^{\text {rd. }}$ ed.) New York: Free Press.

Rogers, EM. 1995. Diffusion of Innovations (4th ed.) New York: Free Press

Rogers, EM \& Scott, KL. 1997. The diffusion of innovations model and outreach from the National Network of Libraries of Medicine to Native American Communities: draft paper presented for the, Pacific Northwest Region Seattle. [online] http:// nnlm.gov/pnr/eval/rogers.html. Accessed 17 October 2002.

Rogers, EM \& Scott, KL. 1999. The Diffusion of Innovations model and outreach from the national network of libraries of medicine to Native American communities. [online] http://nnlm.gov/pnr/eval/rogers.html. Accessed 20 June 2002.

Rosenberg, D. (2000). An Overview of education for librarianship in Anglophone sub-Saharan Africa. In Wise, M. (editor), 2000. Education for Librarianship and Information Science in Africa. Denver: International Academic Publishers, p I I-33.

Sunding, D \& Zilberman, D. 2000. The agricultural innovation processes: research and technology adoption in a changing agricultural sector.[on-line] http://are.berkeley.edu/zilber/innovationchptr.pdf [accessed 22/6/02].

Surry, DW. 1997. Diffusion Theory and Instructional Technology: Paper presented at the Annual Conference of the Association for Educational Communications and Technology (AECT), Albuquerque, New Mexico February 12 - 15, 1997. [online] http:/ /www.gsu.edu/ wwwitr/docs/diffusion/. Accessed 15 November 2002.

Surry, DW \& Farquhar, JD. 1997. Diffusion theory and instructional technology. Journal of Instructional Science and Technology 2(I): 24-36.

Yates, BL. 200I. Adoption of Media Literacy Programs in Schools; Paper presented to the Instructional and Developmental Communication Division International Communication Association Conference Washington, DC, USA May 24-28, 200I. [online] http://www.westgate.edu/ byates/applying.htm. Accessed I 5 November 2002.

\section{Declaration}

The original version of this paper was presented at the ProLISSA Conference in Pretoria in October 2004 (see: http:// www.Dissanet.com) 